\title{
Effects of Calcium and Annatto Tocotrienol Supplementation on Bone Loss Induced by Pantoprazole in Male Rats
}

This article was published in the following Dove Press journal:

Drug Design, Development and Therapy

Kok-Yong Chin (1)

Benjamin Ka Seng Thong (1)

Rhivaldy Faahim Kamalulloh ${ }^{2}$

Nur Vaizura Mohamad'

Sok Kuan Wong (D) ${ }^{1}$

Azlan Mohd Arlamsyah'

Rahma Triliana ${ }^{2}$

Ima Nirwana Soelaiman (D) ${ }^{1}$

'Department of Pharmacology, Faculty of Medicine, Universiti Kebangsaan Malaysia, Cheras 56000, Kuala Lumpur, Malaysia;

${ }^{2}$ Faculty of Medicine, Islamic University of Malang, Kota Malang 65I44, Malang, Indonesia
Correspondence: Kok-Yong Chin Department of Pharmacology, Faculty of Medicine, Universiti Kebangsaan Malaysia, Jalan Yaacob Latif, Bandar Tun Razak, Cheras 56000, Kuala Lumpur, Malaysia

Tel $+603-91459573$

Fax +603-91459547

Email chinkokyong@ppukm.ukm.edu.my
Purpose: Prolonged use of proton pump inhibitors may cause bone loss, and limited therapeutic agents are available to prevent this skeletal side effect. The combination of annatto tocotrienol, a bone anabolic agent, with calcium presents a novel strategy to prevent bone loss caused by proton pump inhibitors. This study aims to compare the effects of calcium alone and in combination with annatto tocotrienol or vitamin $\mathrm{D}_{3}$ (Caltrate Plus) in preventing bone loss caused by pantoprazole.

Methods: Three-month-old Sprague Dawley male rats $(n=30)$ were randomised into five groups ( $\mathrm{n}=6 /$ group). Bone loss was induced by pantoprazole ( $3 \mathrm{mg} / \mathrm{kg}$ p.o.) in four groups, and they were treated concurrently with either calcium carbonate (77 mg p.o.), calcium carbonate (77 mg p.o.) plus annatto tocotrienol (60 mg/kg p.o.) or Caltrate Plus (31 mg p.o.) for 60 days. The rats were euthanised at the end of the experiment, and their femurs were harvested for X-ray micro-computed tomography, bone cellular histomorphometry and bone mechanical strength analysis.

Results: Pantoprazole caused significant deterioration of trabecular bone microstructures but did not affect other skeletal indices. Calcium supplementation with or without annatto tocotrienol prevented the deterioration of trabecular microstructures at the femur but did not improve other skeletal indices. Annatto tocotrienol did not enhance the skeletal actions of calcium, whereas Caltrate Plus did not affect the bone health indices in these rats.

Conclusion: Calcium supplementation per se can prevent the deterioration of bone trabecular microstructures in rats receiving long-term treatment of pantoprazole.

Keywords: osteoblast, osteoclast, osteopaenia, osteoporosis, proton pump inhibitor, vitamin E

\section{Introduction}

Proton pump inhibitors (PPIs) are a class of pharmacological agents used to treat acidrelated disorders, such as gastroesophageal reflux disease, erosive esophagitis and peptic ulcer. ${ }^{1}$ Examples of PPI include omeprazole, pantoprazole and esomeprazole, which rank among the top 100 most frequently prescribed drugs in the US. ${ }^{2}$ They bind covalently to $\mathrm{H}^{+} / \mathrm{K}^{+} /$ATPase of the parietal cells of the stomach to inhibit gastric acid secretion. ${ }^{3}$ PPIs are generally safe and well tolerated by patients. However, their acid suppression action could lead to malabsorptions of several nutrients, such as vitamin B12 (cobalamin), iron, calcium and magnesium. ${ }^{4,5}$ These nutrients play essential roles in skeletal health; thus, a deficiency could contribute to bone loss. For example, cobalamin deficiency increases homocysteine and methylmalonic acid levels, which stimulate osteoclast formation and bone resorption. ${ }^{6}$ Several meta-analyses have 
confirmed that PPI use increases the risk of fracture despite a lack of change in the bone mineral density (BMD). ${ }^{7-10}$ BMD is not a perfect surrogate of bone strength, ${ }^{11}$ and myriad non-BMD factors contribute to fractures. ${ }^{12}$ Thus, the differential effects of PPI on BMD and fracture risk are expected.

Limited recommendations are available to prevent bone loss induced by long-term PPI use. Currently, the US Food and Drug Administration recommends calcium and vitamin D supplementation for individuals at risk of osteoporosis and taking PPI. ${ }^{13}$ It is a logical approach because PPI users may suffer from calcium malabsorption. ${ }^{14}$ However, a metaanalysis of 33 randomised controlled trials revealed that calcium and vitamin D supplementation might not reduce nonvertebral, vertebral or total fracture risk in communitydwelling elderly. ${ }^{15}$ Although this meta-analysis is not without criticisms, ${ }^{16}$ the effects of calcium and vitamin D supplementation on bone health are still debatable. Researchers have been trying other approaches to prevent bone loss. Annatto tocotrienol prevents bone loss in animal models of bone loss induced by sex hormone deficiency and metabolic syndrome. ${ }^{17-19}$ Annatto tocotrienol is derived from annatto bean and contains a unique mixture of vitamin E consisting solely of tocotrienol isomers, particularly gamma- and deltatocotrienol. ${ }^{20}$ A previous study showed that annatto tocotrienol upregulates expression related to bone formation in orchidectomised rats. ${ }^{19}$ In cellular studies, annatto tocotrienol promotes the differentiation of osteoblasts by suppressing the mevalonate pathway. ${ }^{21,22}$ A human trial concluded that 12-week annatto tocotrienol in combination with calcium and vitamin D suppresses bone resorption markers in postmenopausal women with osteopaenia. ${ }^{23}$ However, the effects of calcium and annatto tocotrienol in combination on physical changes in the bone, such as bone microstructure and mechanical strength, have not been attempted.

Therefore, the current study aims to compare the preventive effects of calcium, calcium plus annatto tocotrienol and a commercial formula of calcium plus vitamin $\mathrm{D}$, Caltrate Plus, on bone loss induced by pantoprazole. Pantoprazole is used in the long-term treatment of pathological hypersecretory conditions, such as ZollingerEllison syndrome and idiopathic hypersecretion. ${ }^{24}$ Adult rats were supplemented with pantoprazole for 60 days, which is equivalent to 5 years in humans. ${ }^{25}$ We hypothesise that calcium plus annatto tocotrienol is effective in preventing bone loss induced by pantoprazole and could serve as a candidate regime for PPI users to prevent osteoporosis and its associated fracture.

\section{Materials and Methods Preparation of Treatment Agents}

Pantoprazole (Xepa-Soul Pattinson, Malacca, Malaysia) was crushed into powder and dissolved in normal saline with either calcium carbonate (Bendosen Laboratory Chemicals, Bendosen, Norway) or powdered Caltrate Plus (Pfizer, New York, USA). Annatto tocotrienol (American River Nutrition, USA) consisting of $10 \%$ gamma-tocotrienol and $90 \%$ delta-tocotrienol was diluted in olive oil (Bertolli, Crawley, UK). The dose of Caltrate Plus (31 mg) used in this study was converted from the recommended dose for humans $(600 \mathrm{mg})$ using body surface conversion formula. ${ }^{26}$ It also contains $41 \mathrm{IU}$ vitamin $\mathrm{D}_{3}, 2.6 \mathrm{mg}$ magnesium, $0.4 \mathrm{mg}$ zinc and trace amounts of copper and manganese. The dose of calcium carbonate used $(77 \mathrm{mg}$ ) provided the same amount of elemental calcium as Caltrate Plus. The dose of annatto tocotrienol used [60 $\mathrm{mg} / \mathrm{kg}$ body weight (b.w.)] was derived from previous studies, ${ }^{19}$ which showed that this dose could prevent bone loss in rat models.

\section{Treatment of Animals}

Three-month-old Sprague Dawley male rats $(n=30)$ were purchased from Laboratory Animal Resource Unit, Universiti Kebangsaan Malaysia (Kuala Lumpur, Malaysia). They were housed at Animal Laboratory, Department of Pharmacology, Faculty of Medicine, Universiti Kebangsaan Malaysia (Cheras, Malaysia) in ventilated plastic cages under standard conditions (25 $\pm 2^{\circ} \mathrm{C}, 12 / 12 \mathrm{~h}$ dark/light cycle) and given tap and standard rat chow (Goldcoin, Klang, Malaysia) throughout the study period. After acclimatisation for a week, the rats were randomised into five groups ( $\mathrm{n}=6 /$ group). Four groups were given pantoprazole ( $3 \mathrm{mg} / \mathrm{kg}$ b.w.) via oral gavage daily in the morning, whereas another group was given equivolume of normal saline. Allocation of treatment regime (calcium carbonate, Caltrate Plus, annatto tocotrienol and the respective vehicles) is listed in Table 1.

The body weight of the rats was monitored weekly using a digital balance. The rats were euthanised after 60 days of treatment through ketamine/xylazine overdose. Their femurs were harvested for subsequent analysis. The femurs were cleaned of soft tissues and weighed. The length and diameter of the femurs were measured using a calliper. The protocol of this study was reviewed and approved by Universiti Kebangsaan Malaysia Animal Ethics Committee (approval code: FAR/PP/2018/KOK 
Table I Treatment Regimes of the Rats

\begin{tabular}{|l|l|l|}
\hline Group & Morning & Evening \\
\hline $\begin{array}{l}\text { Normal control } \\
(\mathrm{NC})\end{array}$ & $\begin{array}{l}\text { Normal saline; oral } \\
\text { gavage }\end{array}$ & $\begin{array}{l}\text { Olive oil; oral } \\
\text { gavage }\end{array}$ \\
\hline $\begin{array}{l}\text { Negative control } \\
(\mathrm{PPI})\end{array}$ & $\begin{array}{l}\text { Pantoprazole [3 mg/kg } \\
\text { body weight (b.w.)]; oral } \\
\text { gavage }\end{array}$ & $\begin{array}{l}\text { Olive oil; oral } \\
\text { gavage }\end{array}$ \\
\hline $\begin{array}{l}\text { Calcium-treated } \\
\text { (PPI+Ca) }\end{array}$ & $\begin{array}{l}\text { Pantoprazole (3 mg/kg b. } \\
\text { w.) }+ \text { calcium carbonate } \\
(77 \text { mg); oral gavage }\end{array}$ & $\begin{array}{l}\text { Olive oil; oral } \\
\text { gavage }\end{array}$ \\
\hline $\begin{array}{l}\text { Calcium and } \\
\text { annatto } \\
\text { tocotrienol-treated } \\
\text { (PPI+Ca+TT) }\end{array}$ & $\begin{array}{l}\text { Pantoprazole (3 mg/kg b. } \\
\text { (77 mg); oral gavage }\end{array}$ & $\begin{array}{l}\text { Annatto } \\
\text { tocotrienol } \\
\text { (60 mg/kg b.w.); } \\
\text { oral gavage }\end{array}$ \\
\hline $\begin{array}{l}\text { Caltrate Plus- } \\
\text { treated (PPI+CP) }\end{array}$ & $\begin{array}{l}\text { Pantoprazole (3 mg/kg b. } \\
\text { w.) }+ \text { Caltrate } \\
\text { Plus (3I mg); oral gavage }\end{array}$ & $\begin{array}{l}\text { Olive oil; oral } \\
\text { gavage }\end{array}$ \\
\hline
\end{tabular}

YONG/26-SEPT./945-JAN.-2019-DEC.-2019). Principles and guides to the ethical use of laboratory animals by Universiti Kebangsaan Malaysia were followed during animal handling.

\section{Micro-Computed Tomography Analysis}

The skeletal microstructure of the rats was assessed using Skyscan 1076 Scanner (Skyscan, Kartuizersweg Kontich, Belgium). Three-dimensional trabecular and cortical bone microstructures were analysed using CTAn software (SkyScan, Kartuizersweg Kontich, Belgium). The volume of interest for trabecular bone was the metaphyseal region of the distal femur, starting from $1.5 \mathrm{~mm}$ to the lowest margin of the femoral epiphyseal growth plate. A total of 200 slices were obtained from this point onwards and extending proximally. For cortical bone, another 200 slices volume of interest was selected at the middiaphysis region of the femur located $7.0 \mathrm{~mm}$ from the distal growth plate. The scans were performed at $70 \mathrm{kVp}$ and $100 \mu \mathrm{A}$ with high resolution. The trabecular parameters derived included bone volume (BV/TV), trabecular thickness (Tb.Th), trabecular number (Tb.N), trabecular separation (Tb.Sp), structural model index (SMI) and connectivity density. The cortical parameters derived included cortical thickness (Cr.Th), cortical area (Cr.Ar), tissue area (Tt.Ar) and the ratio of cortical area to tissue area (Cr.Ar/ Tt.Ar).

\section{Bone Cellular Histomorphometry}

The right femurs were cleaned of soft tissue after harvesting and decalcified in phosphate-buffered $10 \%$ formalin solution with ethylenediaminetetraacetic acid (5.5\%) for 2 months. Then, the bone samples were processed into paraffin blocks and sectioned at $5 \mu \mathrm{m}$ longitudinally with a microtome (Leica Biosystem, Leica RM2235, Nussloch, Germany). The bone slides were rinsed with xylene and rehydrated with a series of alcohol solutions and stained with haematoxylin for $10 \mathrm{~min}$. Next, they were rinsed with bluing reagents for $10 \mathrm{~s}$ and stained with eosin for $5 \mathrm{~min}$. Finally, the slides were dehydrated with a series of alcohol solutions and mounted for microscopic observation.

The slides were examined using a light microscope and analysed using a cellSens Standard software (Olympus Corp, Tokyo, Japan). The region of interest is $1.5 \mathrm{~mm}$ below the lowest margin of the epiphyseal growth plate of the distal femur. A Weibel grid of 21 lines and 42 points was used for quantitative measures of the histological features. The lines of the grid intersecting with the trabecular bone, bone cells or osteoid were defined as bone (BS), osteoblast (Ob.S), osteoclast (Oc.S) or osteoid surface (OS). The points of the grid intersecting with the trabecular bone or osteoid were defined as bone (BV) or osteoid volume (OV). ${ }^{27}$ The histomorphometric parameters derived from this method include osteoblast surface (Ob.S/BS), osteoclast surface (Oc.S/BS), eroded surface (ES/BS), osteoid surface (OS/BS), osteoid volume (OV/BV).

\section{Bone Mechanical Strength Test}

The mechanical strength of the femur was tested using a 3-point bending test with a precision universal tester (Autograph AG-10kNG; Shimadzu, Kyoto, Japan) with Trapezium X material testing operation software. In this test, the distal and proximal ends of the femur were supported by rounded edge-free notches with $10 \mathrm{~mm}$ distance in between. A blunt-end aluminium roller stamp was lowered gradually $(5 \mathrm{~mm} / \mathrm{min})$ until the strength of $1 \mathrm{~N}$ was achieved. The study was terminated automatically when a loss of force $>20 \mathrm{~N}$ or a linear change of $2 \mathrm{~mm}$ was identified. The Trapezium $\mathrm{X}$ software received the data and calculated the load $(\mathrm{N})$, displacement $(\mathrm{mm})$, stiffness $(\mathrm{N} / \mathrm{mm})$, stress $\left(\mathrm{N} / \mathrm{mm}^{2}\right)$, strain $(\%)$ and Young's modulus $\left(\mathrm{N} / \mathrm{mm}^{2}\right)$.

\section{Statistical Analysis}

Normality of data was determined using the Shapiro-Wilk test. All data were normally distributed and were analysed 
using parametric tests. Comparison of body weight adopted a time $\times$ treatment design and thus was analysed using mixeddesign ANOVA with small effect analysis. Other parameters which involved end-point measurement were tested using one-way ANOVA with post-hoc pairwise comparison (Tukey or Dunnett T3). All data were presented as mean \pm standard error of the mean. Statistical significance was considered at $\mathrm{p}<0.05$. Statistical analysis was conducted using Statistical Package for Social Sciences (IBM, Armonk, USA).

\section{Results}

Body weight significantly changed with time ( $\mathrm{p}<0.001)$, but the interaction between time and treatment was not significant $(p=0.166)$. All groups, except the PPI $+C P$ group, experienced a significant increase in body weight with time $(p<0.05)$. However, no significant difference in body weight was found among the groups at baseline, Day 30 and Day 60 of the experiment ( $\mathrm{p}>0.05)$ (Figure 1A). In addition, no significant difference in femoral weight, length and diameter was found among the groups ( $p>0.05$ ) (Figure 1B-D).

Three-dimensional reconstruction of the trabecular and cortical bones is depicted in Figure 2. Apparent deterioration of the trabecular network occurred in the rats treated with pantoprazole compared with the normal control. The destruction of the trabecular network was partially prevented in the pantoprazole-treated rats. However, the cortical bone showed no apparent changes among the groups (Figure 2). Quantitatively, BV/TV, Tb.N and Tb.Th decreased significantly, whereas Tb.Sp and SMI increased significantly after the pantoprazole treatment $(\mathrm{p}<0.05)$. Calcium supplementation with and without tocotrienol prevented the changes in BV/TV, Tb.Th and Tb.Sp $(\mathrm{p}<0.05)$. Calcium supplementation per se prevented the changes in SMI, and calcium supplementation combined with tocotrienol prevented the changes in $\mathrm{Tb}$. $\mathrm{N}(\mathrm{p}<0.05)$. Caltrate Plus did not prevent the changes in trabecular bone caused by pantoprazole. Administration of

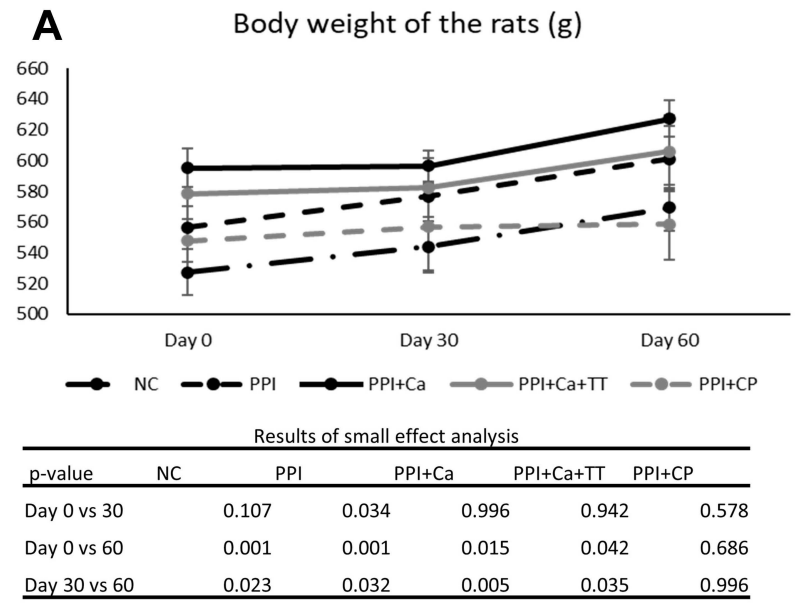

\section{Femoral length $(\mathrm{mm})$}

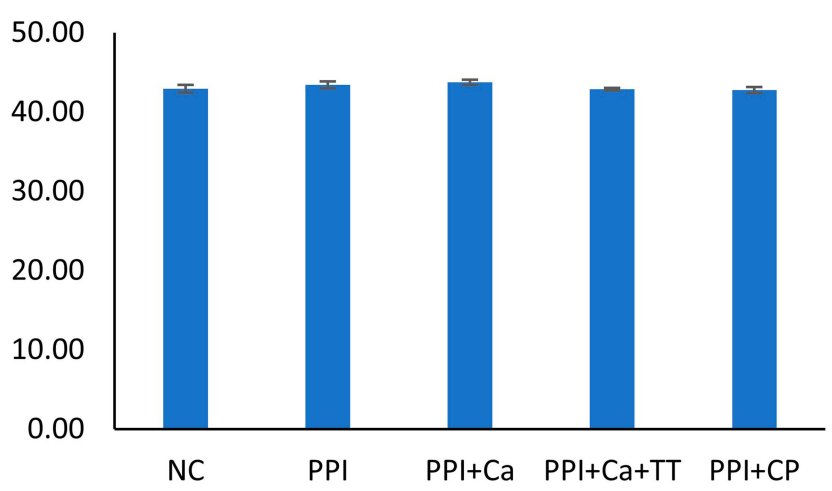

B

Femoral weight (g)

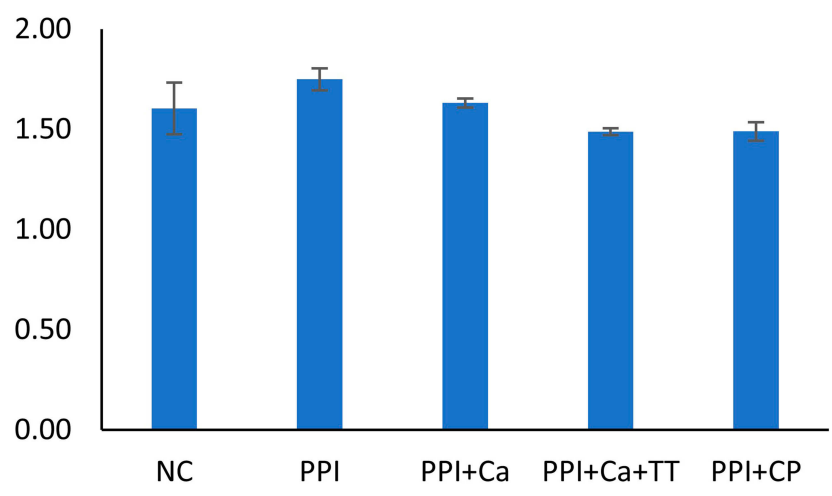

D Femoral diameter $(\mathrm{mm})$

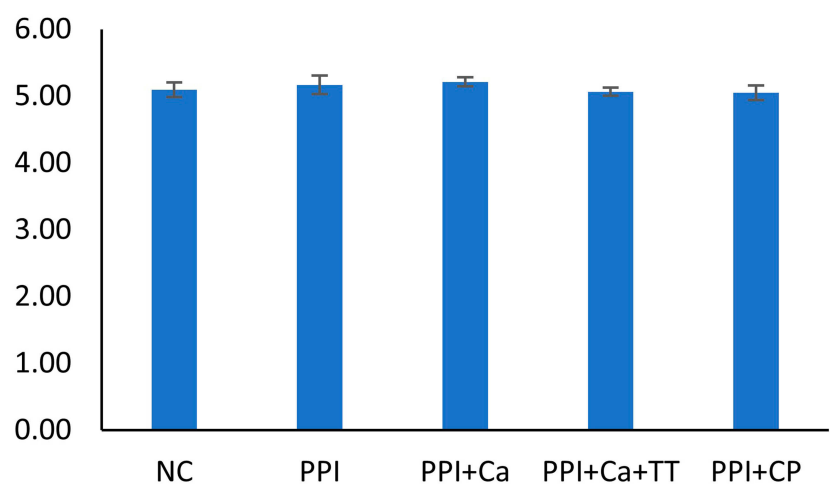

Figure I Body weight $(\mathbf{A})$, femoral weight $(\mathbf{B})$, length $(\mathbf{C})$ and diameter $(\mathbf{D})$ of the rats in different groups. No significant inter-group difference was found ( $>>0.05$ ). Abbreviations: NC, normal control; PPI, pantoprazole/negative control; PPI+Ca, pantoprazole group treated with calcium; PPI+Ca+TT, pantoprazole group treated with calcium and annatto tocotrienol; PPI+CP, pantoprazole group treated with Caltrate Plus. 
Trabecular bone
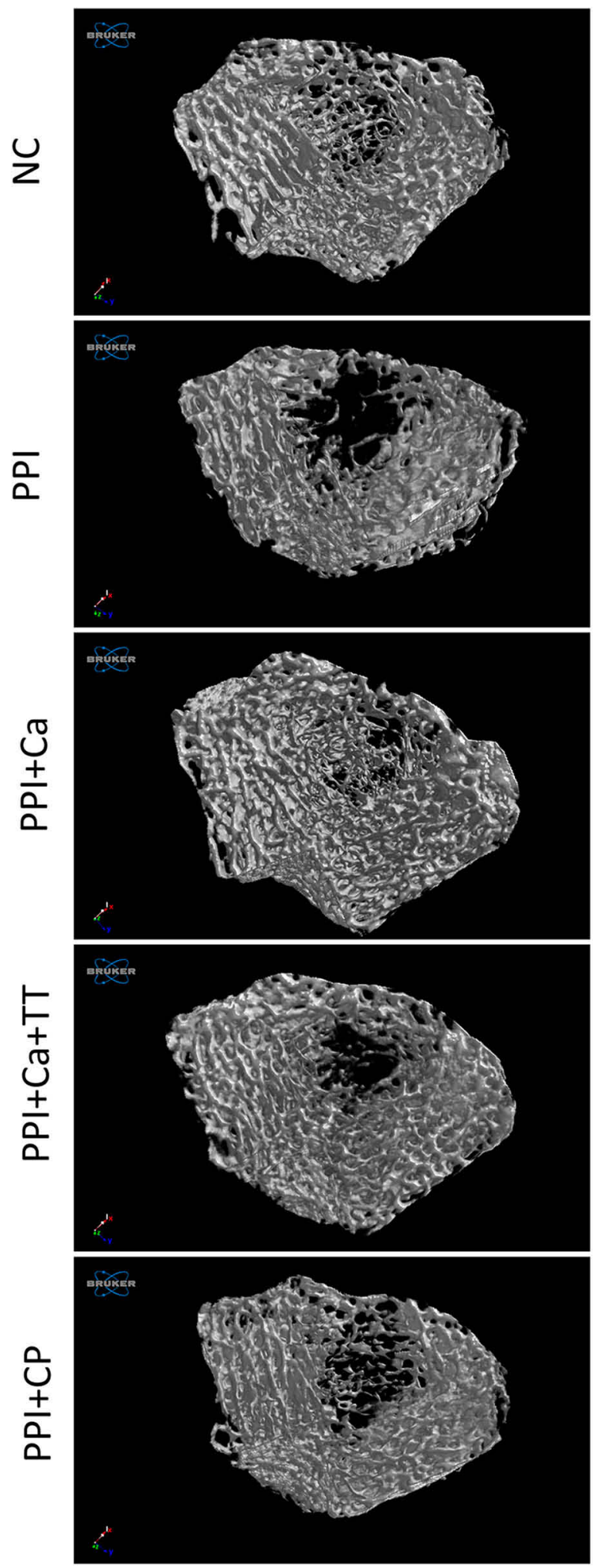

\section{Cortical bone}
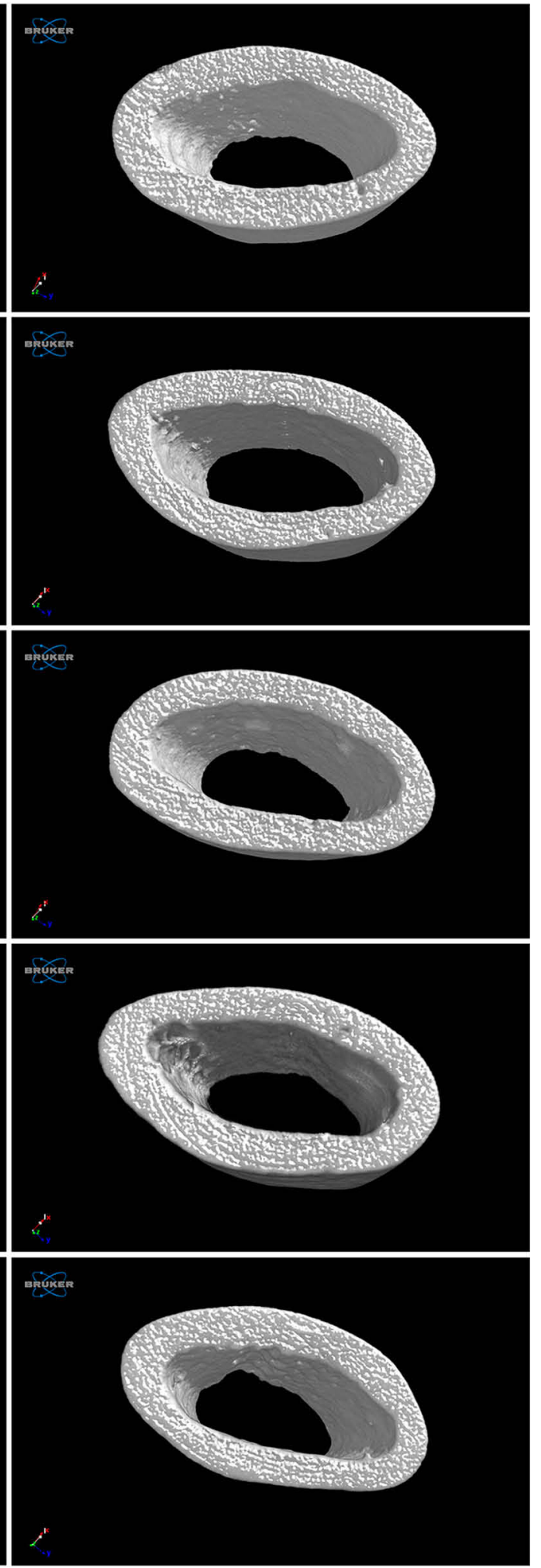

Figure 2 Three-dimensional reconstruction of the trabecular and cortical microstructures of the femoral bones of the rats.

Abbreviations: NC, normal control; PPI, pantoprazole/negative control; PPI+Ca, pantoprazole group treated with calcium; PPI+Ca+TT, pantoprazole group treated with calcium and annatto tocotrienol; $\mathrm{PPI}+\mathrm{CP}$, pantoprazole group treated with Caltrate Plus. 

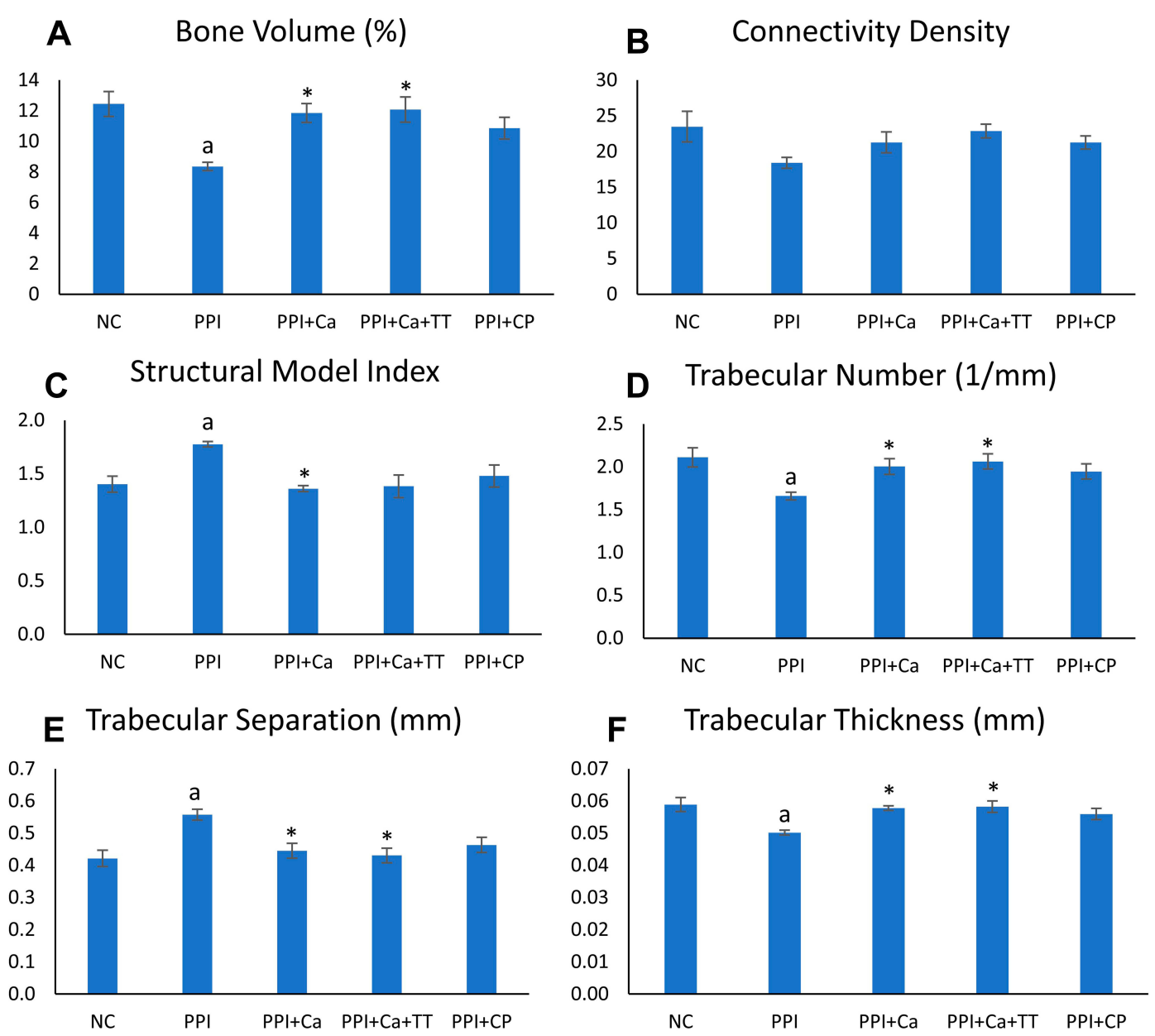

\section{G Cortical Thickness ( $\mathrm{mm})$}

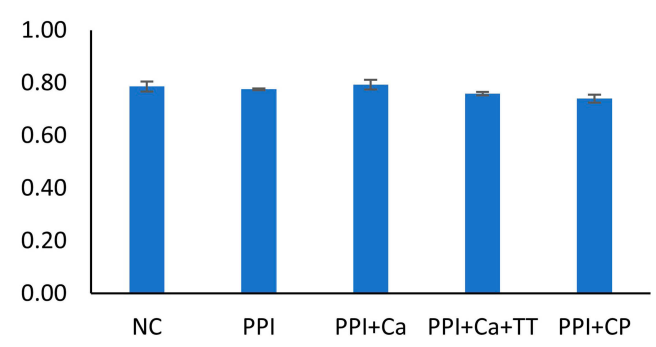

\section{H Cortical Area $\left(\mathrm{mm}^{2}\right)$}
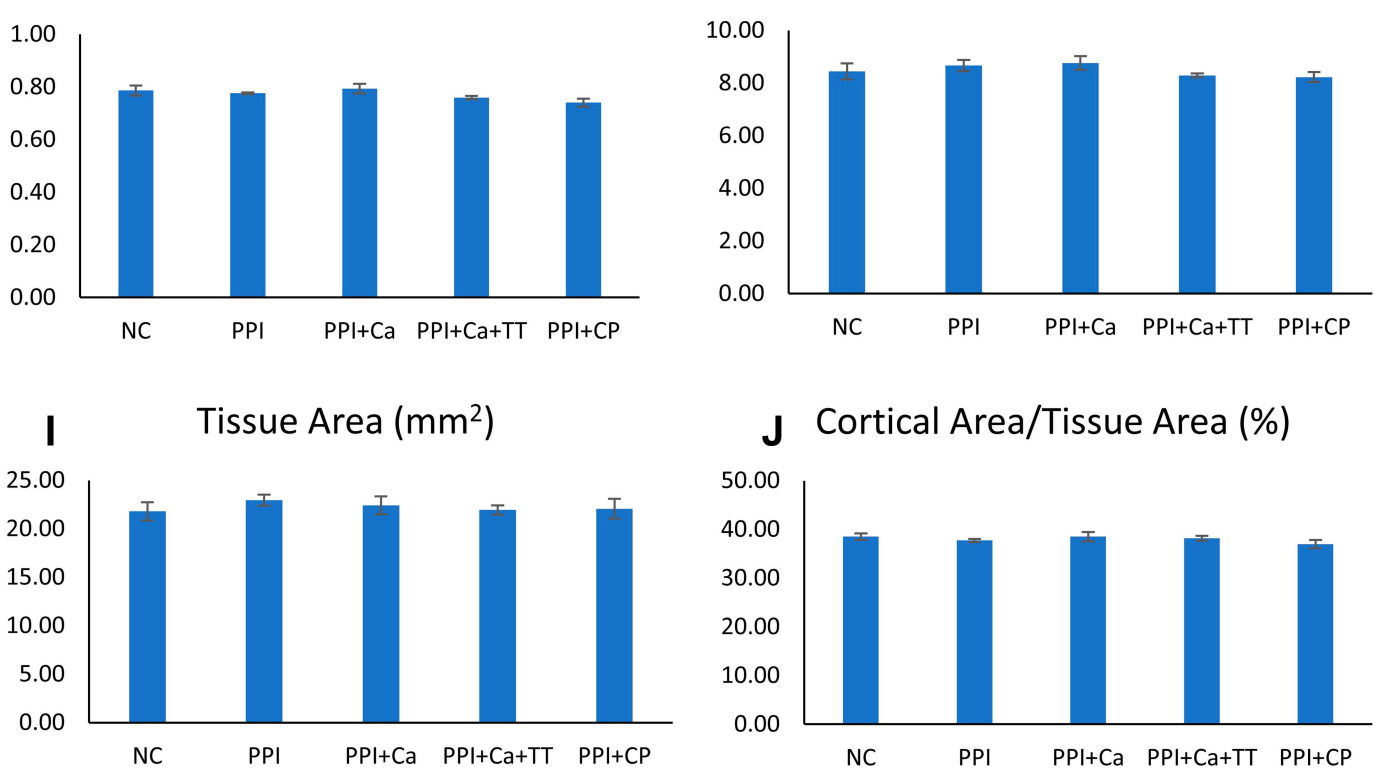

Figure 3 Trabecular and cortical microstructures of the rats. The trabecular indices evaluated include bone volume (A), connectivity density (B), structural model index (C), trabecular number (D), trabecular separation (E) and trabecular thickness (F). The cortical indices evaluated include cortical thickness $(\mathbf{G})$, cortical area (H), tissue area

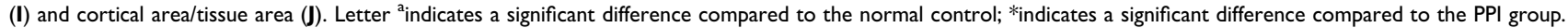
Abbreviations: NC, normal control; PPI, pantoprazole/negative control; PPI+Ca, pantoprazole group treated with calcium; PPI+Ca+TT, pantoprazole group treated with calcium and annatto tocotrienol; PPI+CP, pantoprazole group treated with Caltrate Plus. 


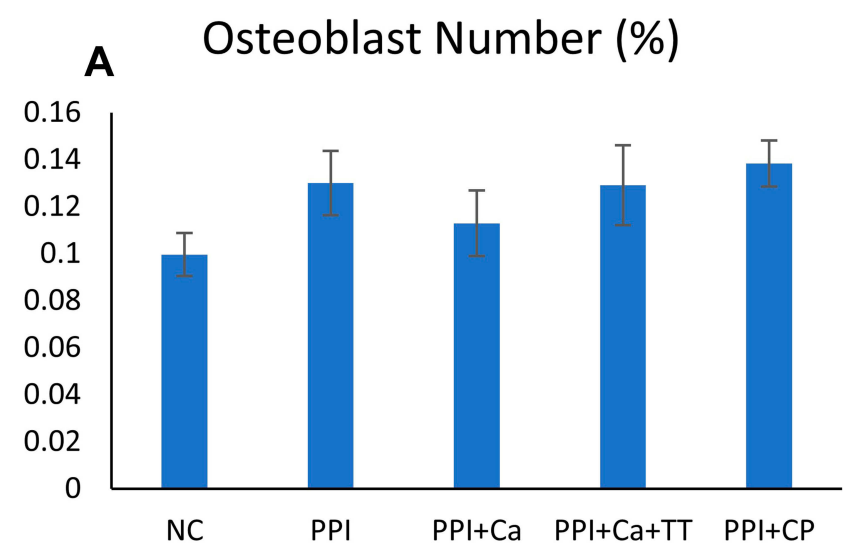

C Osteoid Surface (\%)

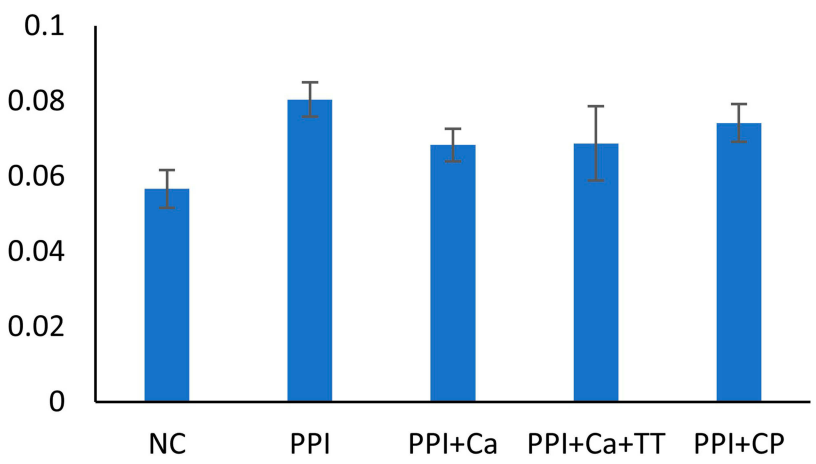

E Eroded Surface (\%)

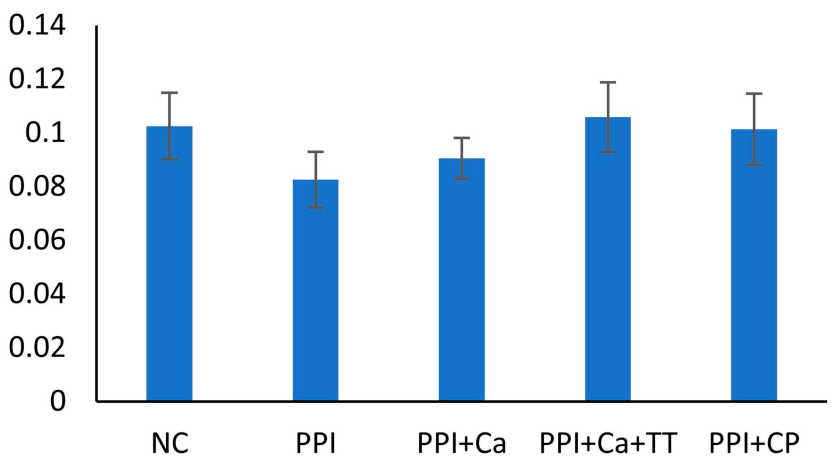

\section{B Osteoclast Number (\%)}

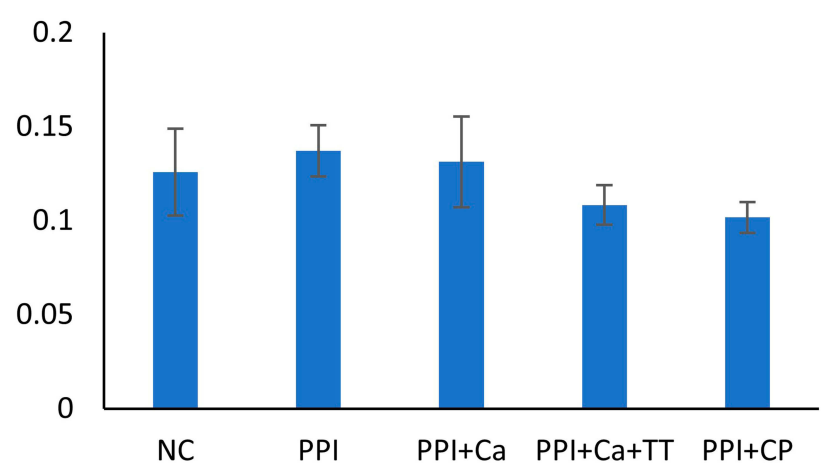

D Osteoid Volume (\%)

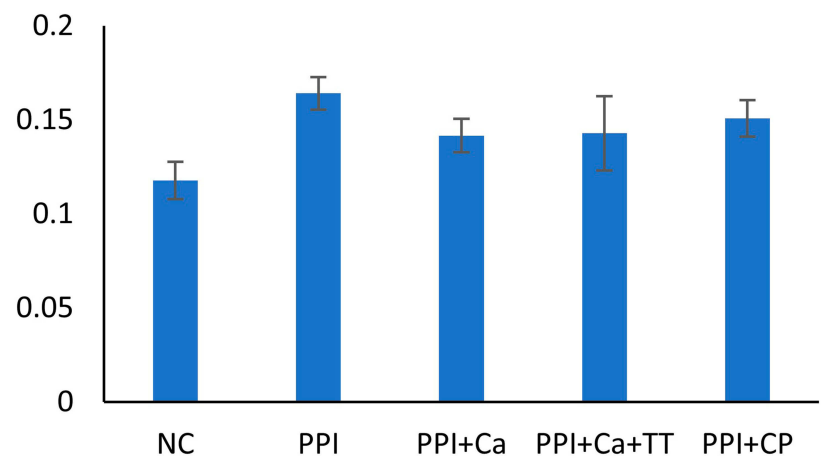

Figure 4 Bone cellular indices of the rats evaluated using the Weibel grid technique, which include osteoblast number (A), osteoclast number $(\mathbf{B})$, osteoid surface (C), osteoid volume (D) and eroded surface (E). No significant inter-group difference was found $(p>0.05)$.

Abbreviations: NC, normal control; PPI, pantoprazole/negative control; PPI+Ca, pantoprazole group treated with calcium; PPI+Ca+TT, pantoprazole group treated with calcium and annatto tocotrienol; PPI+CP, pantoprazole group treated with Caltrate Plus.

pantoprazole with or without other treatments did not alter the cortical parameters (Ct.Th, Ct.Ar, Tt.Ar and Ct.Ar/Tt.Ar) of the rats (Figure 3).

Bone cellular histomorphometry revealed no significant changes in Ob.N, Oc.N, ES/BS, Os/BS and OV/BV among the groups $(\mathrm{p}>0.05)$ (Figures 4 and 5). A similar observation was obtained with the mechanical parameters, whereby the differences in load, displacement, stiffness, stress, strain and Young's modulus were not significant among all groups $(\mathrm{p}>0.05)$ (Figure 6).

\section{Discussion}

Pantoprazole caused limited adverse changes in the trabecular microstructure of the femur of the rats but did not alter the cortical bone microstructure, cellular indices and mechanical strength. Calcium supplementation with or 


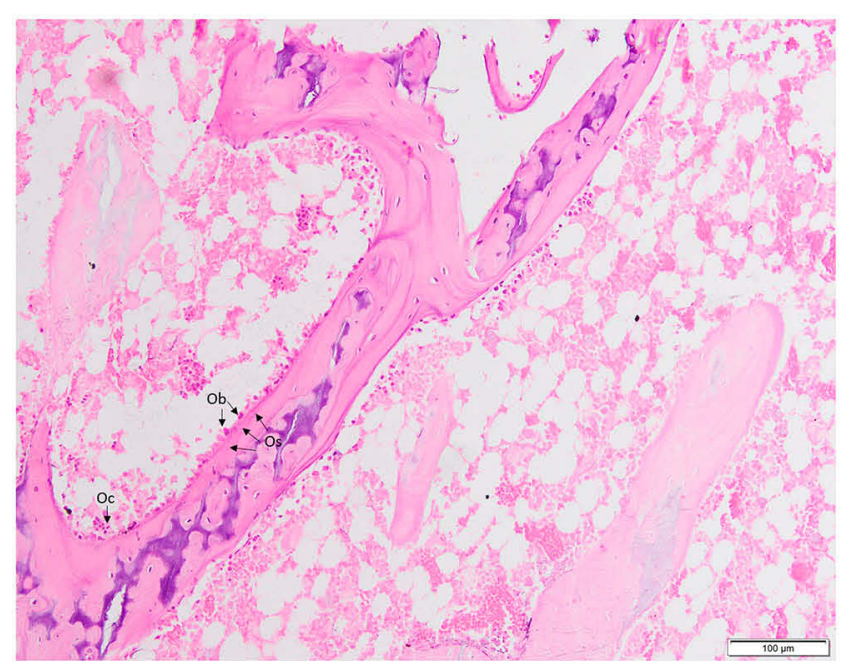

Normal control

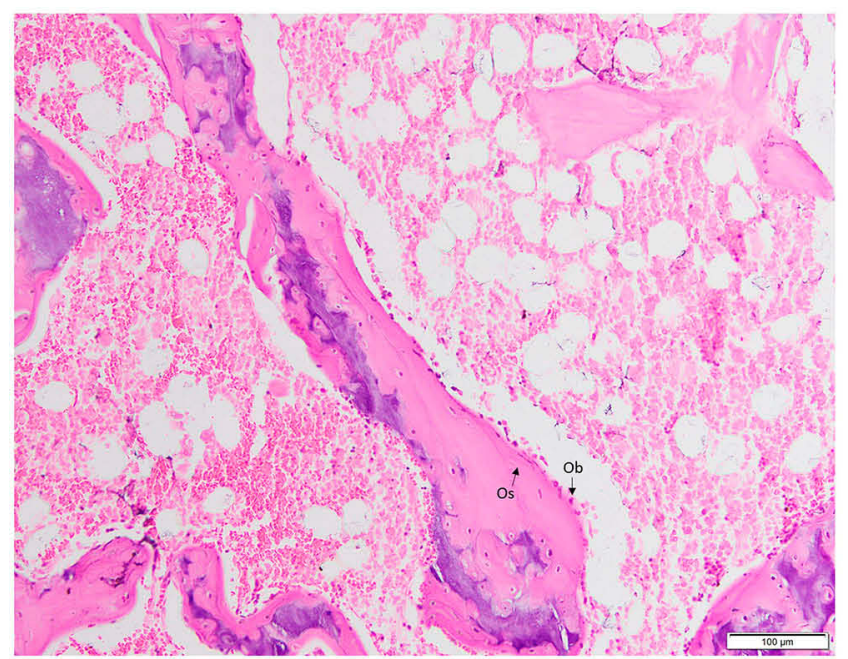

Pantoprazole + Calcium

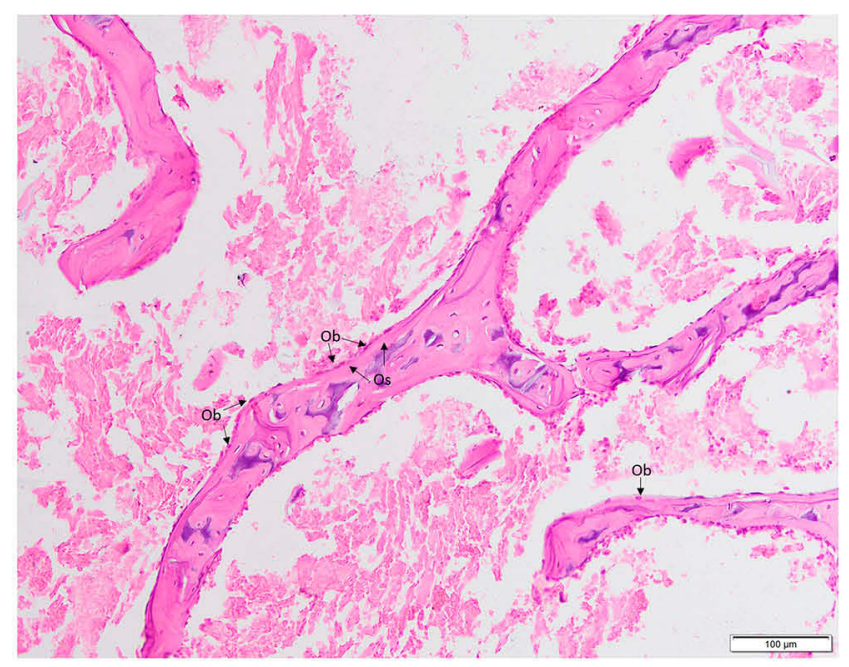

Pantoprazole + Caltrate Plus

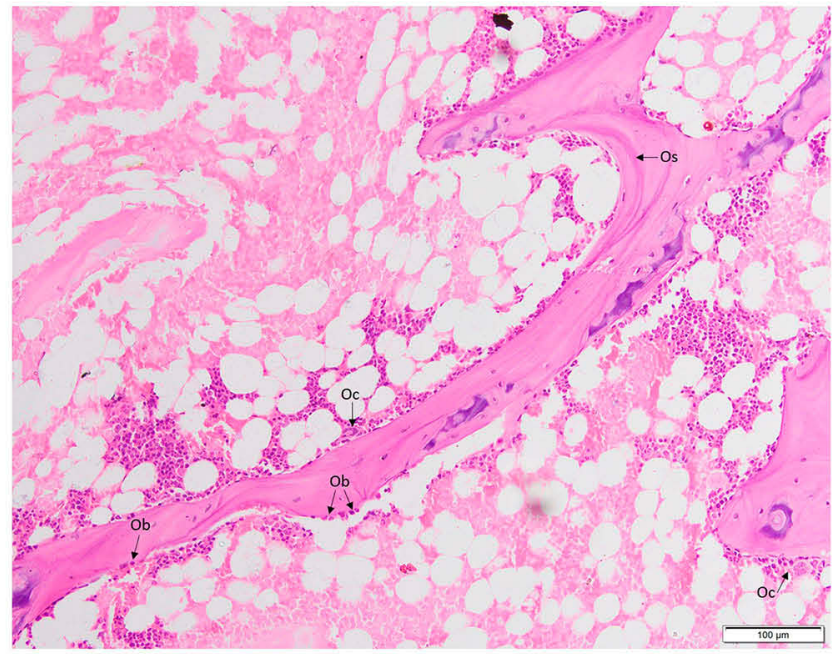

Negative control (Pantoprazole)

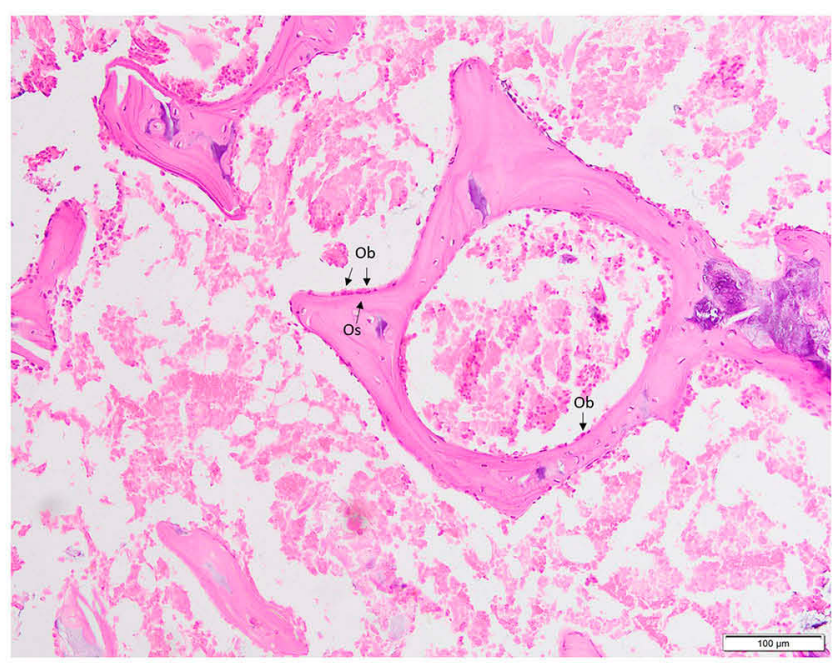

Pantoprazole + Calcium + Annatto tocotrienol

Figure 5 Micrographs of the trabecular bones.

Abbreviations: Ob, osteoblast; Oc, osteoclast; Os, osteoid. 


\section{A}

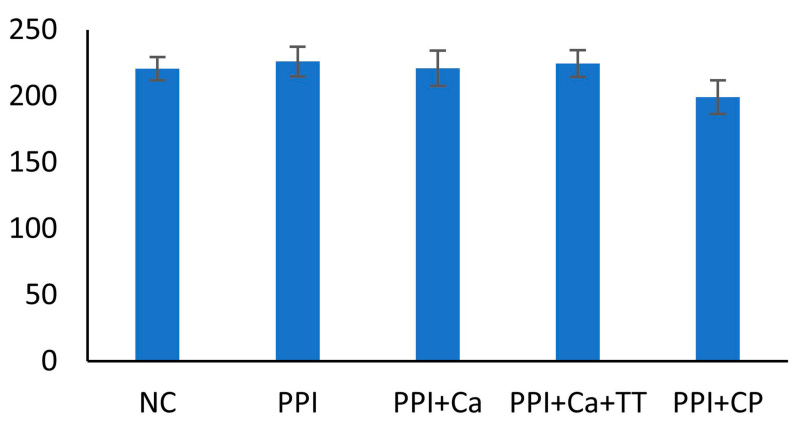

C Displacement ( $\mathrm{mm}$ )
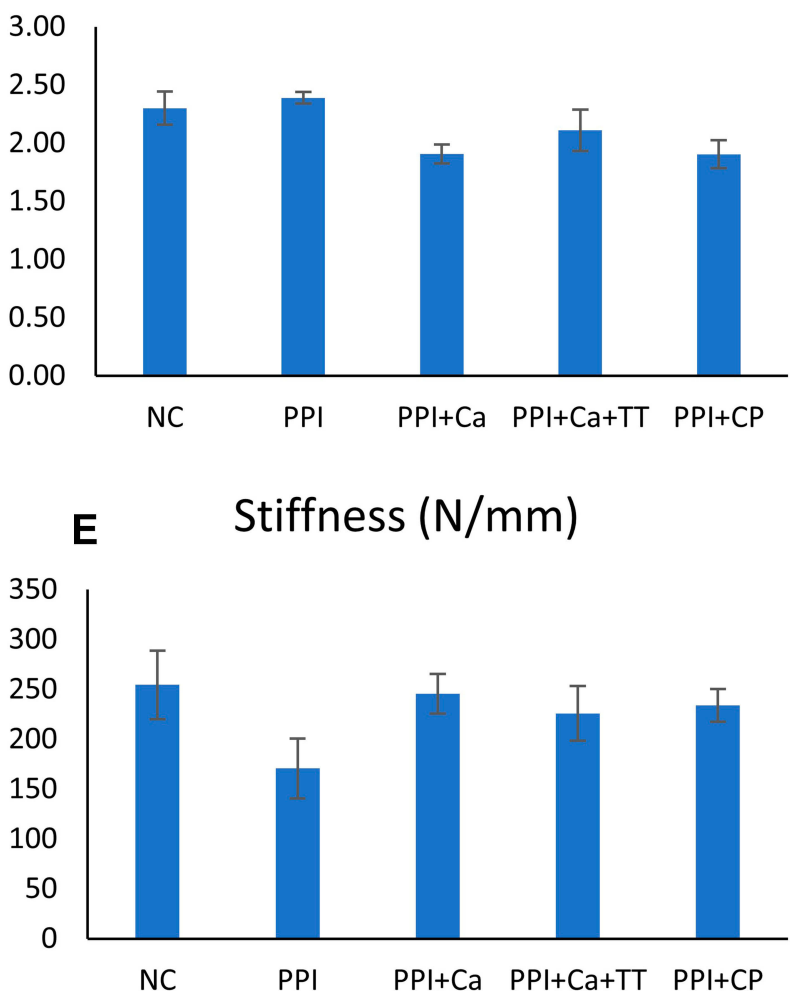

B

Stress (Pa)

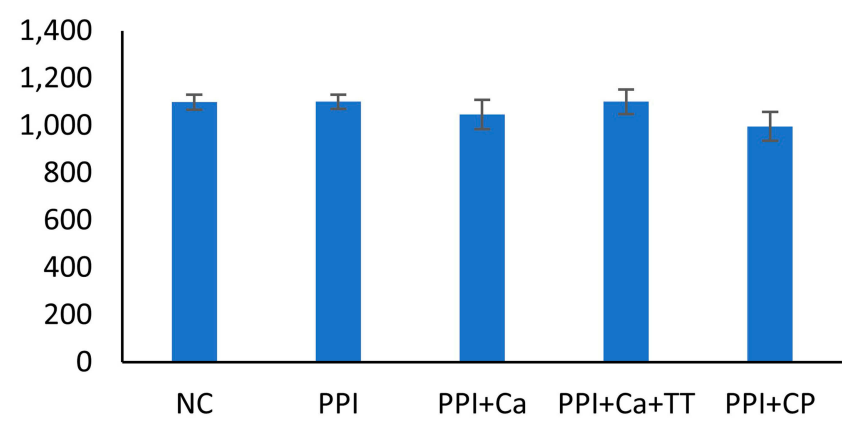

D

Strain (\%)

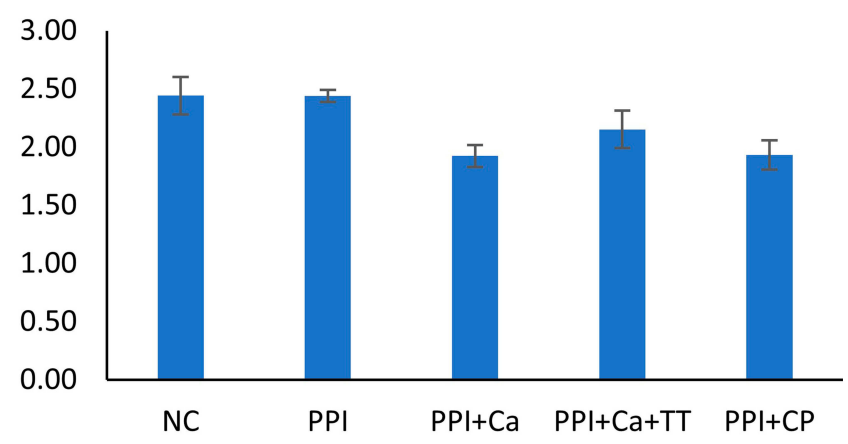

F Young's Modulus (N/mm²)

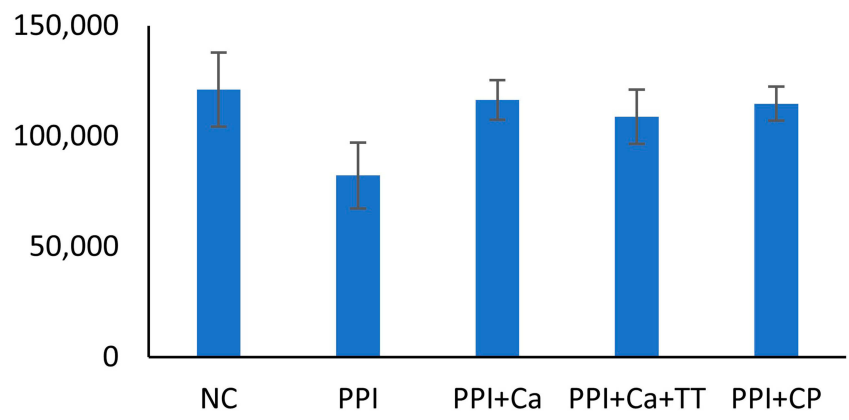

Figure 6 Bone mechanical strength indices of the rats evaluated using the three-point-bending test, which include load (A), stress (B), displacement (C), strain (D), stiffness (E) and Young's modulus (F). No significant inter-group difference was found $(p>0.05)$.

Abbreviations: NC, normal control; PPI, pantoprazole/negative control; PPI+Ca, pantoprazole group treated with calcium; PPI+Ca+TT, pantoprazole group treated with calcium and annatto tocotrienol; PPI+CP, pantoprazole group treated with Caltrate Plus.

without annatto tocotrienol prevented the adverse changes in trabecular bone caused by pantoprazole. However, all treatment regimes did not affect the other skeletal indices of the rats receiving pantoprazole.

In this study, pantoprazole impaired the trabecular microstructures of the rats by reducing BV/TV, Tb.N and Tb.Th while increasing Tb.Sp and SMI. However, it exerted no effects on the cortical microstructures. The structure of trabecular bone provides a large surface-tovolume ratio for bone remodelling to occur; therefore, rapid changes can be observed with external stimuli like pantoprazole. By contrast, Matuszewska et al (2016) did not detect any changes in bone microstructure of Wistar rats treated with pantoprazole ( $3 \mathrm{mg} / \mathrm{kg}$ for 84 days). ${ }^{28}$ Similarly, Veggar et al (2017) did not observe changes in femoral trabecular and cortical structures of mice with impaired mobility and treated with pantoprazole (100 mg/kg bw daily, 3 weeks). However, they reported a marginally higher lumbar Tb.Th in these mice compared with the untreated mice. ${ }^{29}$ 
In the present study, calcium supplementation with or without annatto tocotrienol prevented the degenerative changes in the trabecular microstructure of the rats treated with pantoprazole in this study. A previous study found that dietary calcium supplementation prevents the cadmiuminduced deterioration of femoral microstructure (Tb.N and $\mathrm{Cr} . \mathrm{Th})$ in rats. ${ }^{30}$ In addition, calcium supplementation through drinking water prevents the destruction of trabecular structure in male rats due to testosterone deficiency induced by buserelin. ${ }^{18,31}$ By contrast, calcium supplementation does not enhance the trabecular bone structure in lactating rats. ${ }^{32}$ Surprisingly, annatto tocotrienol did not act synergistically with calcium carbonate in this study to further enhance its effects on bone microstructure. A previous report indicated that annatto tocotrienol prevents the deterioration of bone microstructure in animal models of bone loss induced by testosterone deficiency, ${ }^{18,19,31}$ oestrogen deficiency ${ }^{33}$ and metabolic syndrome. ${ }^{17}$ The results of the present study suggest that the bone anabolic effects of annatto tocotrienol are limited and overshadowed by the effects of calcium supplementation.

Bone cellular histomorphometry quantifies the number of osteoblasts and osteoclasts as well as the consequence of their actions, such as osteoid synthesis and bone erosion. ${ }^{34}$ In the present study, pantoprazole did not affect the bone cell numbers, osteoid surface/volume and eroded surface of the rats. Similarly, a previous study found that the osteoclast surface of mice with impaired mobility does not change with pantoprazole treatment. ${ }^{29}$ However, pantoprazole decreases the viability of osteoclast-like cells derived from human peripheral blood mononuclear cells and increases the viability of human primary osteoblasts derived from excised femoral head. ${ }^{35,36}$ Gene expressions related to osteoclastogenesis and osteoblastogenesis are not altered with pantoprazole in these in vitro studies. ${ }^{35,36}$

Calcium supplementation with or without annatto tocotrienol did not alter bone cellular histomorphometric indices in rats receiving pantoprazole. This observation is in agreement with a previous study showing that calcium in drinking water does not alter bone cell number and activities in male rats with testosterone deficiency. ${ }^{31}$ However, calcium supplementation reduces erosion surface but not osteoblast and osteoclast numbers in lactating rats. ${ }^{32}$ Previous studies found that annatto tocotrienol improves bone cellular indices in various animal models of bone loss..$^{17,31,37,38}$ Interaction between annatto tocotrienol and pantoprazole might exist, which hinders the beneficial actions of annatto tocotrienol on bone cells.
Reduced bone strength is the ultimate consequence of osteoporosis. This study showed that pantoprazole treatment for 2 months did not affect the bone strength of the rats despite the degenerative changes in trabecular bone microstructures. The 3-point bending test was performed at the mid-diaphysis of the femur, which consists mainly of cortical bone. No significant change was observed in the cortical structure; thus, the lack of effect on bone strength is expected. Pantoprazole does not alter bone strength at the femoral diaphysis, femoral neck, lumbar vertebra and humeral diaphysis of mice with impaired mobility and treated with pantoprazole. ${ }^{29}$ At $200 \mathrm{mg} / \mathrm{kg}$ i.p. for 8 weeks, pantoprazole also did not change the bone strength in a model of posterolateral lumbar spinal fusion in female rats. A rat fracture-healing model showed that pantoprazole $(100 \mathrm{mg} / \mathrm{kg}$, i.p. for 5 weeks) reduces the bending stiffness at the fractured bone but not at the contralateral unfractured bone. ${ }^{39}$

Calcium supplementation with or without annatto tocotrienol did not improve the biomechanical parameters of the rats taking pantoprazole in this study. Similarly, calcium supplementation of the rat dams does not improve bone strength of pups. ${ }^{32}$ This observation contradicted the findings of Mohamad et al (2018) that calcium in drinking water improves the femoral load and Young's modulus of rats with testosterone deficiency induced by buserelin. ${ }^{18}$ Annatto tocotrienol also improves the bone strength of the rats in some models of osteoporosis ${ }^{17,18}$ but is ineffective in this case. Our observation is similar to a previous finding that annatto tocotrienol ( $60 \mathrm{mg} / \mathrm{kg}$ oral for 2 months) could not improve bone strength of orchidectomised male rats. ${ }^{40}$ The discrepancy between bone strength and microstructure may stem from the different regions of femur measured.

Surprisingly, Caltrate Plus, which contains calcium, trace elements and vitamin $D_{3}$, was not effective in improving any of the skeletal health parameters. Likewise, annatto tocotrienol did not enhance the effects of calcium supplementation. We suspect a potential drug interaction between pantoprazole and tocotrienols or vitamin D. These agents are catabolised, at least partly, by cytochrome 3A4 (CYP3A4). Pantoprazole upregulates the expression of CYP3A $4,{ }^{41}$ which catabolises tocotrienols and vitamin $\mathrm{D},{ }^{42,43}$ thus reducing the level and effectiveness of these compounds in the rats. This speculation should be validated in future studies.

Several limitations should be addressed in this study. Firstly, we did not determine the effects of pantoprazole on the gastric $\mathrm{pH}$, serum and bone mineral and cobalamin levels, which may be related to its effects on skeletal 
health. Secondly, the serum levels of tocotrienols and vitamin D were not determined; hence, we do not know the absorption and bioavailability of these compounds. Thirdly, the parathyroid level of the rats was not quantified; therefore, we did not know whether pantoprazole could cause calcium deficiency in this model and whether it was averted with the treatments. Fourthly, the serum bone formation and resorption markers were not evaluated to highlight the effects of treatment on bone turnover. These assays can be incorporated in future studies to provide a comprehensive view of the mechanism of calcium in preventing bone loss induced by pantoprazole.

\section{Conclusion}

Pantoprazole causes adverse effects on trabecular bone microstructure, but it does not affect bone strength or cellular histomorphometric indices. Calcium supplementation with or without annatto tocotrienol prevents the degenerative changes of pantoprazole on trabecular bone microstructure. Annatto tocotrienol does not enhance the effects of calcium significantly in this regard. Therefore, chronic users of proton pump inhibitors may consider calcium supplementation as a pharmacological strategy to prevent bone loss.

\section{Acknowledgments}

We thank Universiti Kebangsaan Malaysia for funding this study (FF-2018-404). We also thank American River Nutrition for providing the annatto tocotrienol used in this study.

\section{Disclosure}

The authors declare no conflicts of interest in this work.

\section{References}

1. Yu LY, Sun LN, Zhang XH, et al. A review of the novel application and potential adverse effects of proton pump inhibitors. Adv Ther 2017;34(5):1070-1086. doi:10.1007/s12325-017-0532-9

2. Fuentes AV, Pineda MD, Venkata KCN. Comprehension of top 200 prescribed drugs in the US as a resource for pharmacy teaching, training and practice. Pharmacy. 2018;6(2):43.

3. Shin JM, Sachs G. Pharmacology of proton pump inhibitors. Curr Gastroenterol Rep. 2008;10(6):528-534. doi:10.1007/s11894-0080098-4

4. Eusebi LH, Rabitti S, Artesiani ML, et al. Proton pump inhibitors: risks of long-term use. $J$ Gastroenterol Hepatol. 2017;32 (7):1295-1302.

5. Thong BKS, Ima-Nirwana S, Chin KY. Proton pump inhibitors and fracture risk: a review of current evidence and mechanisms involved. Int J Environ Res Public Health. 2019;16(9):E1571. doi:10.3390/ ijerph16091571
6. Dai Z, Koh W-P. B-vitamins and bone health-a review of the current evidence. Nutrients. 2015;7(5):3322-3346. doi:10.3390/nu7053322

7. Liu J, Li X, Fan L, et al. Proton pump inhibitors therapy and risk of bone diseases: an update meta-analysis. Life Sci. 2019;218:213-223. doi:10.1016/j.lfs.2018.12.058

8. Zhou B, Huang Y, Li H, Sun W, Liu J. Proton-pump inhibitors and risk of fractures: an update meta-analysis. Osteoporos Int. 2016;27 (1):339-347. doi:10.1007/s00198-015-3365-x

9. Nassar Y, Richter S. Proton-pump inhibitor use and fracture risk: an updated systematic review and meta-analysis. J Bone Metab. 2018;25 (3):141-151. doi:10.11005/jbm.2018.25.3.141

10. Poly TN, Islam MM, Yang HC, Wu CC, Li YJ. Proton pump inhibitors and risk of hip fracture: a meta-analysis of observational studies. Osteoporos Int. 2019;30(1):103-114. doi:10.1007/s00198018-4788-y

11. Friedman AW. Important determinants of bone strength: beyond bone mineral density. J Clin Rheumatol. 2006;12(2):70-77. doi:10.1097/ 01.rhu.0000208612.33819.8c

12. Berry SD, Kiel DP. Chapter 33 - falls as risk factors for fracture. In: Marcus R, Feldman D, Dempster DW, Luckey M, Cauley JA, editors. Osteoporosis. Fourth ed. San Diego: Academic Press; 2013:803-815.

13. Administration UFaD. FDA drug safety communication: possible increased risk of fractures of the hip, wrist, and spine with the use of proton pump inhibitors. Published 2011. Available from: https://www.fda.gov/drugs/postmarket-drug-safety-informationpatients-and-providers/fda-drug-safety-communication-possibleincreased-risk-fractures-hip-wrist-and-spine-use-protonpump\#AdditionalInformationforPatientsandConsumers. Accessed June 22, 2020.

14. Yang Y-X. Chronic proton pump inhibitor therapy and calcium metabolism. Curr Gastroenterol Rep. 2012;14(6):473-479. doi:10.1007/s11894-012-0290-4

15. Zhao J-G, Zeng X-T, Wang J, Liu L. Association between calcium or vitamin $\mathrm{D}$ supplementation and fracture incidence in community-dwelling older adults: a systematic review and meta-analysis. JAMA. 2017;318 (24):2466-2482. doi:10.1001/jama.2017.19344

16. Bischoff-Ferrari HA, Dawson-Hughes B, Willett WC. Issues of trial selection and subgroup considerations in the recent meta-analysis of Zhao and colleagues on fracture reduction by calcium and vitamin D supplementation in community-dwelling older adults. Osteoporosis Int. 2018;29(9):2151-2152. doi:10.1007/s00198-018-4587-5

17. Wong SK, Chin KY, Suhaimi FH, Ahmad F, Ima-Nirwana S. Exploring the potential of tocotrienol from Bixa orellana as a single agent targeting metabolic syndrome and bone loss. Bone. 2018;116:8-21. doi:10.1016/j.bone.2018.07.003

18. Mohamad NV, Ima-Nirwana S, Chin KY. Effect of tocotrienol from Bixa orellana (annatto) on bone microstructure, calcium content, and biomechanical strength in a model of male osteoporosis induced by buserelin. Drug Des Devel Ther. 2018;12:555-564. doi:10.2147/ DDDT.S158410

19. Chin KY, Ima-Nirwana S. Effects of annatto-derived tocotrienol supplementation on osteoporosis induced by testosterone deficiency in rats. Clin Interv Aging. 2014;9:1247-1259. doi:10.2147/CIA.S67016

20. Frega N, Mozzon M, Bocci F. Identification and estimation of tocotrienols in the annatto lipid fraction by gas chromatography-mass spectrometry. J Am Oil Chem Soc. 1998;75(12):1723-1727. doi:10. 1007/s11746-998-0323-1

21. Wan Hasan WN, Chin K-Y, Abd Ghafar N, Soelaiman IN. Annattoderived tocotrienol promotes mineralisation of MC3T3-E1 cells by enhancing BMP-2 protein expression via inhibiting RhoA activation and HMG-CoA reductase gene expression. Drug Des Devel Ther. 2020;14:969-976. doi:10.2147/DDDT.S224941

22. Wan Hasan WN, Abd Ghafar N, Chin KY, Ima-Nirwana S. Annattoderived tocotrienol stimulates osteogenic activity in preosteoblastic MC3T3-E1 cells: a temporal sequential study. Drug Des Devel Ther. 2018;12:1715-1726. 
23. Shen CL, Yang S, Tomison MD, Romero AW, Felton CK, Mo H. Tocotrienol supplementation suppressed bone resorption and oxidative stress in postmenopausal osteopenic women: a 12-week randomised double-blinded placebo-controlled trial. Osteoporos Int. 2018;29(4):881-891. doi:10.1007/s00198-017-4356-x

24. Metz DC, Soffer E, Forsmark CE, et al. Maintenance oral pantoprazole therapy is effective for patients with Zollinger-Ellison syndrome and idiopathic hypersecretion. Am J Gastroenterol. 2003;98 (2):301-307. doi:10.1111/j.1572-0241.2003.07262.x

25. Andreollo NA, Santos EF, Araújo MR, Lopes LR. Rat's age versus human's age: what is the relationship? Arq Bras Cir Dig. 2012;25 (1):49-51. doi:10.1590/S0102-67202012000100011

26. Reagan-Shaw S, Nihal M, Ahmad N. Dose translation from animal to human studies revisited. FASEB J. 2008;22(3):659-661. doi:10.1096/ fj.07-9574LSF

27. Saif A, Norazlina M, Ima Nirwana S. Quantification of bone histomorphometric parameters using the weibel technique in animals. Med Health. 2016;11(2):278-288. doi:10.17576/MH.2016.1102.16

28. Matuszewska A, Nowak B, Rzeszutko M, et al. Effects of long-term administration of pantoprazole on bone mineral density in young male rats. Pharmacol Rep. 2016;68(5):1060-1064. doi:10.1016/j. pharep.2016.06.012

29. Vegger JB, Bruel A, Thomsen JS. Pantoprazole, a proton pump inhibitor, does not prevent botulinum toxin induced disuse osteopenia in mice. J Musculoskelet Neuronal Interact. 2017;17(3):162-175.

30. Huang H, Liu L, Zhao Z, Fu FU, Wang W, Xu Q. Protective effects of moderate $\mathrm{Ca}$ supplementation against $\mathrm{Cd}$-induced bone damage under different population-relevant doses in young female rats. Nutrients. 2019;11(4):849. doi:10.3390/nu11040849

31. Mohamad NV, Soelaiman IN, Chin KY. Effects of tocotrienol from Bixa orellana (annatto) on bone histomorphometry in a male osteoporosis model induced by buserelin. Biomed Pharmacother. 2018;103:453-462. doi:10.1016/j.biopha.2018.04.083

32. Suntornsaratoon P, Charoenphandhu N, Krishnamra N. Fortified tuna bone powder supplementation increases bone mineral density of lactating rats and their offspring. J Sci Food Agric. 2018;98 (5):2027-2034. doi:10.1002/jsfa.8688

33. Abdul-Majeed S, Mohamed N, Soelaiman IN. The use of delta-tocotrienol and lovastatin for anti-osteoporotic therapy. Life Sci. 2015;125:42-48. doi:10.1016/j.1fs.2014.12.012
34. Allen MR, Burr DB. Chapter 8 - techniques in histomorphometry. In: Burr DB, Allen MR, editors. Basic and Applied Bone Biology. (Second ed. Academic Press; 2019:141-158.

35. Prause M, Seeliger C, Unger M, Rosado Balmayor E, van Griensven M, Haug AT. Pantoprazole decreases cell viability and function of human osteoclasts in vitro. Mediators Inflamm. 2015;2015:413097. doi:10.1155/2015/413097

36. Prause $M$, Seeliger C, Unger $M$, van Griensven $M$, Haug AT. Pantoprazole increases cell viability and function of primary human osteoblasts in vitro. Injury. 2014;45(8):1156-1164. doi:10.1016/j. injury.2014.05.005

37. Chin KY, Abdul-Majeed S, Mohamed N, Ima-Nirwana S. The effects of tocotrienol and lovastatin Co-supplementation on bone dynamic histomorphometry and bone morphogenetic protein-2 expression in rats with estrogen deficiency. Nutrients. 2017;9(2):E143. doi:10.33 90/nu9020143

38. Chin KY, Abdul-Majeed S, Fozi NF, Ima-Nirwana S. Annatto tocotrienol improves indices of bone static histomorphometry in osteoporosis due to testosterone deficiency in rats. Nutrients. 2014;6 (11):4974-4983. doi:10.3390/nu6114974

39. Histing T, Stenger D, Scheuer C, et al. Pantoprazole, a proton pump inhibitor, delays fracture healing in mice. Calcif Tissue Int. 2012;90 (6):507-514. doi:10.1007/s00223-012-9601-x

40. Chin KY, Gengatharan D, Mohd Nasru FS, et al. The effects of annatto tocotrienol on bone biomechanical strength and bone calcium content in an animal model of osteoporosis due to testosterone deficiency. Nutrients. 2016;8(12):E808.

41. Masubuchi N, Li AP, Okazaki O. An evaluation of the cytochrome P450 induction potential of pantoprazole in primary human hepatocytes. Chem Biol Interact. 1998;114(1):1-13. doi:10.1016/ S0009-2797(98)00031-3

42. Abe C, Uchida T, Ohta M, Ichikawa T, Yamashita K, Ikeda S. Cytochrome P450-dependent metabolism of vitamin $\mathrm{E}$ isoforms is a critical determinant of their tissue concentrations in rats. Lipids. 2007;42(7):637-645. doi:10.1007/s11745-007-3064-2

43. Wang Z, Lin YS, Zheng XE, et al. An inducible cytochrome P450 3A4-dependent vitamin D catabolic pathway. Mol Pharmacol. 2012;81(4):498-509. doi:10.1124/mol.111.076356

\section{Publish your work in this journal}

Drug Design, Development and Therapy is an international, peerreviewed open-access journal that spans the spectrum of drug design and development through to clinical applications. Clinical outcomes, patient safety, and programs for the development and effective, safe, and sustained use of medicines are a feature of the journal, which has also been accepted for indexing on PubMed Central. The manuscript management system is completely online and includes a very quick and fair peer-review system, which is all easy to use. Visit http://www. dovepress.com/testimonials.php to read real quotes from published authors. 